\title{
Outcomes of open distal aortic aneurysm repair in patients with chronic DeBakey type I dissection
}

\author{
Joseph S. Coselli, MD, ${ }^{\mathrm{a}, \mathrm{b}, \mathrm{c}}$ Susan Y. Green, MPH, ${ }^{\mathrm{a}, \mathrm{b}, \mathrm{c}}$ Samantha Zarda, MS, ${ }^{\mathrm{a}, \mathrm{b}, \mathrm{c}}$ Courtney C. Nalty, MSPH, ${ }^{\mathrm{a}}$ \\ Matt D. Price, MS, ${ }^{a, b, c}$ Michael S. Hughes, BM, ${ }^{a, b, c}$ Ourania Preventza, MD, ${ }^{\text {a,b,c }}$ \\ Kim I. de la Cruz, MD, ${ }^{\mathrm{a}, \mathrm{b}, \mathrm{c}}$ and Scott A. LeMaire, MD ${ }^{\mathrm{a}, \mathrm{b}, \mathrm{c}}$
}

Objectives: In patients with acute DeBakey type I dissection, endovascular repair of the descending thoracic
aorta during proximal aortic repair is an increasingly popular approach to preventing distal aortic sequelae and
subsequent repair. To better define the risks and outcomes associated with these secondary operations, we exam-
ined our contemporary experience with open distal aortic repair in patients with chronic type I aortic dissection.

\begin{abstract}
Methods: Data were collected between January 2005 and June 2013 regarding 198 consecutive open descending thoracic $(n=27)$ or thoracoabdominal $(n=171)$ aortic repairs performed in patients with chronic type I dissection. The median interval between the dissection onset and the subsequent distal operation was 5.0 years (interquartile range, 2.4-10.5 years). A total of 110 repairs (56\%) were performed in patients with genetic disorders.

Results: There were 14 early deaths (7\%). Permanent paraplegia developed in 2 patients (1\%), 5 patients (3\%) had permanent stroke, and 9 patients $(5 \%)$ had permanent renal failure. Factors associated with early death included greater age $(P=.01)$, chronic obstructive pulmonary disease $(P=.01)$, clamping proximal to the left subclavian artery $(P=.004)$, and use of hypothermic circulatory arrest $(P=.002)$. The use of cold renal perfusion $(P<.001)$ was associated with early survival. Early death was not associated with genetic disorders, emergency surgery, or extent of aortic repair. There were 36 late deaths, yielding an actuarial 8-year survival of $65.6 \% \pm 5.9 \%$. At 7 years, freedom from repair failure was $95.7 \% \pm 1.7 \%$, and freedom from subsequent repair for disease progression was $84.8 \% \pm 4.6 \%$.
\end{abstract}

Conclusions: In survivors of DeBakey type I aortic dissection with distal aneurysm, open repair of the descending thoracic or thoracoabdominal aorta can be performed with excellent early survival, acceptable morbidity, and relatively few late aortic events. (J Thorac Cardiovasc Surg 2014;148:2986-94)

? Supplemental material is available online.

Acute DeBakey type I aortic dissection is life threatening and necessitates emergency open proximal aortic repair. However, the ideal approach to such repair remains controversial. Although many centers, including our own, generally prefer to limit the extent of repair in these cases

From the Division of Cardiothoracic Surgery, ${ }^{\text {a }}$ Michael E. DeBakey Department of Surgery, Baylor College of Medicine, Houston, Tex; Department of Cardiovascular Surgery, ${ }^{\mathrm{b}}$ Texas Heart Institute, Houston, Tex; and Baylor St Luke's Medical Center, ${ }^{\mathrm{c}}$ Houston, Tex.

Disclosures: Joseph S. Coselli is a consultant for Vascutek Terumo and receives royalties for the Terumo branched graft for thoracoabdominal aortic repair. Ourania Preventza reports consulting fees for Medtronic. Scott A. LeMaire reports consulting fees for Baxter and Medtronic. All other authors have nothing to disclose with regard to commercial support.

Read at the 94th Annual Meeting of The American Association for Thoracic Surgery, Toronto, Ontario, Canada, April 26-30, 2014.

Received for publication April 23, 2014; revisions received July 14, 2014; accepted for publication July 16, 2014; available ahead of print Sept 8, 2014.

Address for reprints: Joseph S. Coselli, MD, One Baylor Plaza, BCM 390, Houston, TX 77030 (E-mail: jcoselli@bcm.edu).

$0022-5223 / \$ 36.00$

Copyright (c) 2014 by The American Association for Thoracic Surgery

http://dx.doi.org/10.1016/j.jtcvs.2014.07.048 in the hope of increasing early survival, an alternate strategy is maximizing the initial repair in an attempt to prevent distal aortic dilatation, reduce the need for subsequent distal repair, and increase late survival.

A strategy recently has emerged that includes the antegrade stent-graft placement in the distal arch or proximal descending thoracic aorta (DTA) as part of the evolving frozen elephant trunk (FET) approaches. This increasingly popular approach is thought to limit the distal aortic sequelae described; we and others have selectively explored it. ${ }^{1-4}$ One of the purported advantages of this strategy is the obliteration of the corresponding section of the false lumen through (1) the radial force exerted by the stent-graft or (2) simple thrombosis, thereby reducing the rate of yearly aortic expansion and the need for subsequent "high-risk" surgical repair of the descending thoracic and thoracoabdominal aortic segments. To better define the risks and outcomes associated with these secondary operations, we examined our contemporary experience in patients whose chronic dissection caused late aneurysm formation and necessitated distal aortic repair.

\section{PATIENTS AND METHODS}

\section{Study Enrollment and Patient Characteristics}

Following a protocol approved by the institutional review board at Baylor College of Medicine, we identified 198 consecutive distal aortic 

Abbreviations and Acronyms
DTA $=$ descending thoracic aorta
FET = frozen elephant trunk
HCA = hypothermic circulatory arrest
IQR = interquartile range
SSDI $=$ Social Security Death Index
TAAA $=$ thoracoabdominal aortic aneurysm

repairs (Table 1) necessitated by late aneurysm formation in patients with chronic DeBakey type I aortic dissection. Repairs were performed between January 2005 and June 2013. Before May 2006, data were collected retrospectively; afterward, data were collected prospectively and entered in a departmental research database. Informed consent was obtained from all patients enrolled after protocol approval, and a waiver of consent permitted the inclusion of patients who were unable to provide consent due to their illness and for those who underwent surgery before protocol approval. In regard to study variables, operative mortality (early death) was defined as death within 30 days of surgery or before final hospital discharge, including any death that occurred after transfer to a secondary hospital or long-term acute care facility. Adverse outcome is a composite endpoint that includes operative death and permanent (at hospital discharge) stroke, renal failure necessitating hemodialysis, paraplegia, or paraparesis. ${ }^{5}$ Genetic disorder was defined as having a connective tissue disorder or the onset of aortic disease before age 50 years.

The median age of onset of DeBakey type I aortic dissection was 48.8 years (interquartile range [IQR], 36.4-57.4 years), and the median time to distal aortic repair necessitated by disease progression was 5.0 years (IQR, 2.4-10.5 years). Most patients $(\mathrm{n}=165,83 \%)$ had their proximal repair performed elsewhere. Most repairs involved patients with a complex aortic history; only 1 patient did not have a prior aortic repair. A total of 110 repairs $(56 \%)$ were performed in patients with genetic disorders, including $70(35 \%)$ with a connective tissue disorder.

\section{Follow-up and Outcomes}

Follow-up was obtained by clinic visit, telephone, or written correspondence. Medical records were reviewed for late events, and late deaths also were identified from the Social Security Death Index (SSDI); 6 patients were lost to follow-up but were indicated to be alive by the SSDI. Clinical follow-up was available for 178 of 184 early survivors. The median duration of follow-up for survivors was 3.7 years (range, 0.2-8.7 years; IQR, 2.2-5.6 years). Repair failure was defined as failure directly related to the index distal aortic repair; failures related to prior or subsequent aortic repair (open or endovascular) were not included when determining specific outcomes of the index repair. Late repair for disease progression was defined as subsequent aortic repair in an adjacent aortic section.

\section{Operative Technique}

Our surgical approach to open repair of thoracoabdominal aortic aneurysms (TAAAs) related to chronic dissection (Table 2) has been described. ${ }^{6}$ During extent I and II TAAA repairs and select extent III repairs, left heart bypass is used as part of a multimodal approach to preventing spinal cord ischemia; left heart bypass is established via the left inferior pulmonary vein and the lower DTA. In acute dissection, the false lumen is obliterated during the construction of the proximal anastomosis. In chronic dissection, the thick septum is excised or fenestrated. When dissection extends into the origins of the visceral vessels, the septum is excised or fenestrated, or the false lumen is sutured closed or obliterated by placing a small balloon-expandable stent within the true lumen. Whenever the ostia of the renal arteries are accessible, a cold solution is intermittently delivered to these vessels. ${ }^{7,8}$ The distal anastomosis usually is constructed at the level of the aortic bifurcation (or, occasionally, to each iliac or femoral artery separately). In chronic dissection, the septum is fenestrated if the dissection continues distally. The left renal artery is typically reattached directly to an opening in the Dacron graft or via an 8- or 10-mm Dacron graft. Bowel viability, renal perfusion, and femoral pulses are carefully evaluated at completion.

\section{Data Presentation}

Data were analyzed with Stata IC 13 (StataCorp LP, College Station, Tex). Categoric variables are described as number and percentage. Continuous variables are described as median with IQR. Univariate comparisons were made with the Pearson chi-square test, Fisher exact test, or Kruskal-Wallis equality-of-populations rank test, as appropriate. Survival over time and freedom from late events were estimated by the Kaplan-Meier method.

\section{RESULTS \\ Early Outcomes}

Operative mortality occurred after 14 repairs $(7.0 \%)$, and adverse events occurred after 24 repairs (12.1\%) (Table 3). Permanent stroke occurred after 5 repairs $(2.5 \%)$, permanent paraplegia occurred after 2 repairs $(1.0 \%)$, and permanent renal failure necessitating dialysis occurred after 9 repairs $(4.6 \%)$. Early outcomes were stratified by extent II TAAA repair versus all other repairs and by genetic disorder versus no genetic disorder (Table E1), but no significant differences were found. Of note, patients in both of these selected subgroups were substantially younger when they underwent distal aortic repair; the median ages were 51.8 versus 58.7 years and 47.1 versus 62.0 years, respectively. Early deaths most commonly resulted from stroke or pulmonary complication (Table 4).

Univariate analysis was performed to identify associations with operative mortality and adverse event (Table 5). Older age at the time of distal aortic repair was a risk factor for both events $(P=.01$ and $P=.005$, respectively), as were chronic obstructive pulmonary disease $(P=.01$ and $P=.007)$, aortic clamping proximal to the left subclavian artery $(P=.004$ and $P=.005)$, the use of hypothermic circulatory arrest (HCA) $(P=.002$ and $P=.006)$, and major postoperative complications. Cold renal perfusion appeared to be protective against operative death $(P<.001)$ and adverse events $(P=.03)$.

\section{Late Outcomes}

Late deaths occurred in 36 of 184 early survivors $(19.6 \%)$. Twelve of these deaths were identified as aortic related; 4 were related to repair failure, 2 were related to subsequent repair for disease progression, and 6 were related to additional aortic dissection $(\mathrm{n}=2)$, aortic rupture $(\mathrm{n}=2)$, and nonadjacent aortic reoperation $(\mathrm{n}=2)$. Another 9 late deaths had unknown causes. 
TABLE 1. Preoperative characteristics of 198 distal aortic repairs in patients with chronic DeBakey type I aortic dissection

\begin{tabular}{|c|c|}
\hline Variable & $\begin{array}{l}\text { Median (IQR); } \\
\text { range or no. }(\%)\end{array}$ \\
\hline Age at onset of DeBakey I dissection, y & $\begin{array}{c}48.8(36.4-57.4) \\
12.4-75.4\end{array}$ \\
\hline Age at distal aortic repair, y & $\begin{array}{c}56.6(45.7-62.3) \\
17.4-88.3\end{array}$ \\
\hline $\begin{array}{l}\text { Time from DeBakey type I dissection to distal } \\
\text { aortic repair, y }\end{array}$ & $\begin{array}{c}5.0(2.4-10.5) \\
0.1-28.7\end{array}$ \\
\hline Male & $147(74.2)$ \\
\hline Genetic disorder & $110(55.6)$ \\
\hline Connective tissue disease & $70(35.3)$ \\
\hline Marfan syndrome & $59(29.8)$ \\
\hline Loeys-Dietz syndrome & $5(2.5)$ \\
\hline Other & $6(3.0)$ \\
\hline $\begin{array}{l}\text { Aortic disease onset at }<50 \mathrm{y} \text { and without } \\
\text { CTD }\end{array}$ & $40(20.2)$ \\
\hline Additional aortic dissection & $17(8.6)$ \\
\hline Acute status & $10(5.0)$ \\
\hline DeBakey I & $1(0.5)$ \\
\hline DeBakey II & $1(0.5)$ \\
\hline DeBakey III & $15(7.6)$ \\
\hline Maximum distal aortic diameter, $\mathrm{cm}(\mathrm{n}=189)$ & $6.1(5.5-6.9) ; 3.9-10.8$ \\
\hline $\begin{array}{l}\text { Maximal distal aortic diameter } \geq 8.5 \mathrm{~cm} \\
\quad(\mathrm{n}=189)\end{array}$ & $11(5.8)$ \\
\hline Diabetes & $7(3.6)$ \\
\hline Hypertension & $175(88.4)$ \\
\hline Coronary artery disease & $65(32.8)$ \\
\hline Cerebrovascular disease & $33(16.7)$ \\
\hline Chronic renal insufficiency & $7(3.5)$ \\
\hline Chronic renal failure (dialysis) & $6(3.0)$ \\
\hline Pulmonary disease $(n=193)$ & $71(35.9)$ \\
\hline Chronic obstructive pulmonary disease & $41(20.7)$ \\
\hline Past or current tobacco use $(n=192)$ & $102(51.5)$ \\
\hline Extent of prior proximal aortic replacement* & $197(99.5)$ \\
\hline None $\dagger$ & $1(0.5)$ \\
\hline Ascending aorta/aortic root & $100(50.5)$ \\
\hline Ascending aorta/aortic root + hemiarch & $36(18.2)$ \\
\hline Ascending aorta/aortic root + full arch & $15(7.6)$ \\
\hline $\begin{array}{l}\text { Ascending aorta/aortic root }+ \text { full arch with } \\
\text { elephant trunk }\end{array}$ & $46(23.2)$ \\
\hline Extent of prior distal aortic replacement* & $23(11.6)$ \\
\hline None & $171(86.4)$ \\
\hline Descending thoracic & $12(6.1)$ \\
\hline Extent I TAAA & $5(2.5)$ \\
\hline Extent II TAAA & $3(1.5)$ \\
\hline Extent III TAAA & 0 \\
\hline Extent IV TAAA & 0 \\
\hline Abdominal & $3(1.5)$ \\
\hline Previous endovascular aortic repair $\ddagger$ & $12(6.1)$ \\
\hline Acute symptoms at time of repair & $29(14.7)$ \\
\hline Rupture & $7(3.5)$ \\
\hline $\begin{array}{l}\text { Nonrupture-complicating factor at time of distal } \\
\text { aortic repair }\end{array}$ & $7(3.5)$ \\
\hline Infected graft or endograft & $2(1.0)$ \\
\hline Fistula & $2(1.0)$ \\
\hline
\end{tabular}

TABLE 1. Continued

\begin{tabular}{lc}
\hline \multicolumn{1}{c}{ Variable } & $\begin{array}{c}\text { Median (IQR); } \\
\text { range or no. }(\%)\end{array}$ \\
\hline Pseudoaneurysm & $1(0.5)$ \\
Intercostal or visceral patch aneurysm & $3(1.5)$ \\
\hline$C T D$, Connective tissue disorder; $I Q R$, interquartile range; $T A A A$, thoracoabdominal \\
aortic aneurysm. *For patients with multiple previous aortic repairs, the most compre- \\
hensive extent of prior graft replacement by aortic location is shown. $\dagger$ This patient \\
presented with unrepaired chronic DeBakey type I aortic dissection. The proximal \\
aorta was not sufficiently dilated to warrant repair at the time of distal aortic repair. \\
$\begin{array}{l}\ddagger \text { Includes 4 prior hybrid aortic arch strategies (ie, modified FET, hemiarch with } \\
\text { antegrade TEVAR, and 2-stage hybrid elephant trunk approaches). }\end{array}$
\end{tabular}

Actuarial survival was $79.8 \% \pm 2.9 \%$ at 2 years and $65.6 \% \pm 5.9 \%$ at 8 years (Figure 1 ). There was no significant difference in survival when stratified by extent II versus all other repairs or by genetic disorder versus no genetic disorder (Figure E1). There were 7 site-specific late repair failures (Table E2), which included the development of a pseudoaneurysm in 3 repairs (with an intercostal patch aneurysm in 1 of 3 repairs), fistula in 2 repairs, graft infection in 1 repair, and recurrent graft infection with

TABLE 2. Operative details $(\mathbf{N}=\mathbf{1 9 8})$

\begin{tabular}{lc}
\hline \multicolumn{1}{c}{ Variable } & No. $(\%)$ \\
\hline Urgency of operation & \\
Elective & $156(78.8)$ \\
Urgent & $28(14.1)$ \\
Emergency & $14(7.1)$ \\
Aortic repair details & \\
Extent of repair & \\
$\quad$ DTA & $27(13.6)$ \\
Extent I & $66(33.3)$ \\
Extent II & $80(40.4)$ \\
Extent III & $14(7.1)$ \\
Extent IV & $11(5.6)$ \\
Redo thoracotomy & $22(11.1)$ \\
Extraction of endovascular graft & $11(5.6)$ \\
Reverse elephant trunk & $21(10.6)$ \\
Clamping proximal to left subclavian artery & $78(39.4)$ \\
Intercostal/lumbar artery reattachment & $145(73.2)$ \\
Bypass graft reattachment of intercostal/lumbar & $19(9.6)$ \\
$\quad$ artery & \\
Visceral/renal bypass graft & $59(29.8)$ \\
With 4-branch graft & $12(6.1)$ \\
Visceral/renal endarterectomy & $3(1.5)$ \\
Visceral/renal stent & $2(1.0)$ \\
Iliac/femoral bypass graft & $18(9.1)$ \\
Adjuncts & \\
Cerebrospinal fluid drainage & $182(91.9)$ \\
Left heart bypass* & $140(70.7)$ \\
HCA & $16(8.1)$ \\
Cold renal perfusion & $122(61.6)$ \\
Selective celiac/superior mesenteric artery perfusion & $52(26.3)$ \\
\hline$D T A$, Descending thoracic aorta; $H C A$, hypothermic circulatory arrest. & $*$ Data avail- \\
able for 139 repairs; left heart bypass time averaged 28.2 minutes; & median time \\
was 28.0 minutes (IQR, 23-33). & \\
&
\end{tabular}


TABLE 3. Early outcomes $(\mathbf{N}=198)$

\begin{tabular}{lc}
\hline \multicolumn{1}{c}{ Variable } & $\begin{array}{c}\text { Median (IQR) or } \\
\text { no. }(\%)\end{array}$ \\
\hline Adverse event* & $24(12.1)$ \\
Operative (early) death & $14(7.1)$ \\
In-hospital death & $14(7.1)$ \\
30-d death & $9(4.6)$ \\
Stroke & $10(5.1)$ \\
Permanent & $5(2.5)$ \\
Temporary & $5(2.5)$ \\
Permanent spinal cord deficits & $6(3.0)$ \\
Paraplegia & $2(1.0)$ \\
Paraparesis & $4(2.0)$ \\
Immediate & $4(2.0)$ \\
Delayed & $2(1.0)$ \\
Temporary spinal cord deficits & $19(9.6)$ \\
Acute renal dysfunction & $26(13.1)$ \\
Renal failure necessitating dialysis & $14(7.1)$ \\
$\quad$ Permanent & $9(4.6)$ \\
Temporary & $5(2.5)$ \\
Cardiac complication & $56(28.3)$ \\
Pulmonary complication & $78(39.4)$ \\
Necessitating tracheostomy & $22(11.1)$ \\
Left vocal cord paralysis & $76(38.4)$ \\
Bleeding requiring reoperation & $15(7.6)$ \\
Early survivors: length of intensive care unit stay, d & $4(3-9)$ \\
Early survivors: length of hospital stay, d & $12(9-20)$ \\
\hline IQR, Interquartile range. ${ }^{*}$ Adverse event is a composite endpoint that includes \\
operative death (in-hospital or 30-day death) and permanent (ie, present at hospital \\
discharge) stroke, renal failure, paraplegia, or paraparesis. & \\
&
\end{tabular}

recurrent fistula in 1 repair. Subsequent adjacent aortic repair was necessary to treat disease progression after 17 repairs (Table E3), including 7 open aortic arch repairs (all with prior repair limited to the ascending aorta), 5 further open distal aortic repairs, and 5 endovascular repairs. At 7 years, freedom from repair failure was $95.7 \%$ $\pm 1.7 \%$, freedom from subsequent repair for disease progression was $84.8 \% \pm 4.6 \%$, and freedom from both events was $81.1 \% \pm 4.6 \%$ (Figure $1, B-D$ ).

\section{DISCUSSION}

Survivors of acute DeBakey I type aortic dissection remain at risk for progressive dilation of the remaining dissected aorta. Current guidelines ${ }^{9}$ indicate distal aortic repair for these patients when a diameter-based threshold for repair is reached $(>5.5 \mathrm{~cm})$, aortic growth is rapid $(>0.5 \mathrm{~cm} / \mathrm{y})$, or related symptoms develop. The development of aortic dilatation necessitating distal aortic repair in such patients is highly variable: Progressive dilatation remains indolent in some patients, sparing them additional distal aortic repair, but many DeBakey I survivors eventually require 1 or more distal aortic repairs. Repair for progression of aortic disease has been best described in DeBakey I survivors with Marfan syndrome, and the need for distal aortic repair is estimated to range
TABLE 4. Causes of operative mortality

\begin{tabular}{crl}
\hline Age $(\mathbf{y})$ & POD & \multicolumn{1}{c}{ Cause of death } \\
\hline 73 & 35 & $\begin{array}{l}\text { Pulmonary failure followed by MOF } \\
\text { Subdural hematoma necessitating craniotomy, } \\
\text { liver failure }\end{array}$ \\
83 & 11 & Pulmonary failure followed by MOF \\
62 & 100 & Pulmonary failure followed by sepsis and MOF \\
45 & 34 & Heart failure \\
63 & 0 & Exsanguination due to aortoesophageal fistula at \\
& 8 & Sraft-to-graft anastomosis \\
67 & 6 & Metastatic lung cancer (discovered during repair) \\
48 & 89 & Coagulopathy, bleeding, MOF \\
50 & 5 & Stroke followed by MOF \\
62 & 8 & Sudden cardiopulmonary arrest \\
67 & 4 & Pulmonary failure \\
70 & 50 & Stroke follwed by MOF \\
71 & 10 & Coagulopathy and MOF \\
44 & 5 &
\end{tabular}

from $25 \%$ to $50 \%$ at 5 years. ${ }^{10,11}$ In the current study of 198 such repairs (including 59 repairs in patients with Marfan syndrome), the time from onset of DeBakey type I aortic dissection to the index repair ranged from 44 days to 29 years.

Should survivors of DeBakey I dissection need distal aortic repair, what can they expect? In general, age remains one of the best predictors of early death or adverse event. ${ }^{5}$ Because these patients are approximately a decade younger than is typical for distal aortic repair, ${ }^{12}$ they often do better than expected. In the current study, early death occurred after 14 repairs $(7 \%)$, and adverse events occurred after 24 repairs $(12 \%)$. The rate of permanent paraplegia was particularly low: $1 \%$. This could be due to the "staged" nature of distal repair as necessitated by the progressive nature of DeBakey I aortic dissection. Despite extensive aortic dissection, only the aneurysmal section of the aorta is replaced during repair; thus, in many of these patients, a DTA repair may be followed by a TAAA repair or vice versa. In our study, 23 repairs $(12 \%)$ were performed in patients who had undergone prior distal aortic surgery, and 12 repairs $(6 \%)$ were performed in patients who had undergone prior distal endovascular repair; also, 4 of our 17 late reinterventions involved extent III or IV TAAA repair after previous DTA or extent I TAAA repair. Etz and colleagues ${ }^{13}$ suggest that staged extensive distal aortic repair may facilitate the development of collateral circulation of the spinal cord. Combining this approach with our aggressive strategy of reperfusing select intercostal and lumbar arteries through direct reattachment $(\mathrm{n}=126)$ or via a small-diameter graft $(n=19)$ may offer the best of both worlds.

However, the overall risk of stroke in this series $(\mathrm{n}=10$ [5\%]; only 5 had permanent deficits) was greater than in 
TABLE 5. Potential risk factors for operative (early) death or composite adverse outcome

\begin{tabular}{|c|c|c|}
\hline Variable & $\begin{array}{c}\text { Operative } \\
\text { death }(n=14) \\
P \text { value }\end{array}$ & $\begin{array}{c}\text { Adverse } \\
\text { event } *(n=24) \\
P \text { value } \\
\end{array}$ \\
\hline \multicolumn{3}{|l|}{ Preoperative } \\
\hline $\begin{array}{l}\text { Increasing age at DeBakey I } \\
\text { dissection onset }\end{array}$ & .04 & .07 \\
\hline $\begin{array}{l}\text { Increasing age at distal aortic } \\
\text { repair }\end{array}$ & .01 & .005 \\
\hline Male sex & .8 & .9 \\
\hline $\begin{array}{l}\text { Chronic obstructive pulmonary } \\
\text { disease }\end{array}$ & .01 & .007 \\
\hline Acute symptoms & 1.0 & .5 \\
\hline Rupture at presentation for repair & .4 & .2 \\
\hline Nonrupture-complicating factor $\dagger$ & 1.0 & 1.0 \\
\hline Genetic disorder & .3 & .6 \\
\hline Marfan syndrome & .2 & .1 \\
\hline $\begin{array}{l}\text { Maximal distal aortic diameter } \\
\geq 8.5 \mathrm{~cm}\end{array}$ & .2 & .1 \\
\hline Cerebrovascular disease & 1.0 & .8 \\
\hline Chronic renal dialysis & .4 & .5 \\
\hline Previous distal aortic repair $\ddagger$ & .7 & .2 \\
\hline \multicolumn{3}{|l|}{ Operative } \\
\hline Urgent repair & .1 & .8 \\
\hline Emergency repair & 1.0 & .4 \\
\hline Extraction of endovascular graft & 1.0 & .4 \\
\hline Redo thoracotomy & 1.0 & 1.0 \\
\hline Extent II TAAA repair & .3 & .5 \\
\hline Clamping proximal to LSCA & .004 & .005 \\
\hline Reverse elephant trunk & .2 & .1 \\
\hline Use of cerebrospinal fluid drain & .3 & .4 \\
\hline Use of LHB & .1 & .058 \\
\hline Increasing LHB duration $\S$ & 6 & .6 \\
\hline Use of HCA & .002 & .006 \\
\hline Use of cold renal perfusion $\|$ & $<.001$ & .03 \\
\hline \multicolumn{3}{|l|}{ Postoperative } \\
\hline Pulmonary complications & $<.001$ & $<.001$ \\
\hline Need for tracheostomy & .054 & .2 \\
\hline Permanent stroke & .003 & - \\
\hline Permanent renal failure & .001 & - \\
\hline Permanent paraplegia & 1.0 & - \\
\hline \multicolumn{3}{|c|}{$\begin{array}{l}H C A \text {, Hypothermic circulatory arrest; } L H B \text {, left heart bypass; } L S C A \text {, left subclavian } \\
\text { artery; TAAA, thoracoabdominal aortic aneurysm. *Adverse event is a composite } \\
\text { endpoint that includes operative death (in-hospital or } 30 \text {-day death) and permanent } \\
\text { (ie, present at hospital discharge) stroke, renal failure, paraplegia, or paraparesis. } \\
\dagger \text { Nonrupture-complicating factor at the time of distal aortic repair includes infected } \\
\text { graft or endograft, fistula, pseudoaneurysm, and intercostal or visceral patch aneu- } \\
\text { rysm. } \ddagger \text { Includes both open and endovascular aortic repairs. } \S \text { Available for } 139 \text { of } \\
140 \text { repairs involving LHB. } \| \text { A protective effect was identified (Pearson test } \\
\text { statistic }=14.2697 \text { ). }\end{array}$} \\
\hline
\end{tabular}

our previously published contemporary series of complex distal aortic repairs. ${ }^{12}$ This difference is probably related to the more frequent use of HCA in the current series $(8 \%$, rather than our prior $2 \%)$, which was due to the increased complexity of these cases; we generally reserve HCA for repairs in which a clamp cannot be placed on the aorta proximal to the portion necessitating repair, for example, in cases of enormous aneurysm size, acute rupture, or impingement of an existing stent-graft across the arch, and in repairs extending into the arch $(n=5)$. The use of HCA was strongly associated with early death $(P=.002)$ and adverse event $(P=.006)$. In addition, $74 \%$ of repairs in this series were extensive (extent I or II TAAA repairs), and aortic pathology necessitated initial aortic clamping proximal to the left subclavian artery in many repairs $(n=78 ; 39 \%)$. We found that such clamping was significantly associated with both early death and adverse event; this has been substantiated by others in open repair of chronic distal aortic dissection. ${ }^{14}$ Of note, we found no association between preoperative cerebrovascular disease and early death $(P=1.0)$ or adverse event $(P=.8)$.

Likewise, the rates of postoperative renal dysfunction and permanent renal failure were similar to those in our previously published contemporary TAAA experience ${ }^{12}$ even though cold renal perfusion was used in substantially fewer repairs in the current series $(62 \%$ vs $82 \%)$. Although it is possible that the younger age of our cohort may have been of benefit, univariate analysis associated cold renal perfusion with protection against early death $(P<.001)$ and adverse event $(P=.03)$. Our 2 previous randomized clinical trials also showed the benefits of cold renal perfusion. ${ }^{7,8}$ In the current study, permanent renal failure was associated with early death $(P<.001)$. Of the 9 repairs in patients who developed permanent renal failure, none had preoperative creatinine levels greater than $3.0 \mathrm{mg} / \mathrm{dL}$, and 7 had levels less than $1.5 \mathrm{mg} / \mathrm{dL}$. Thus, it remains difficult to predict renal failure preoperatively.

Although the atherosclerotic process is thought to be an important mechanism in the development of distal aortic aneurysm in patients without aortic dissection, the process behind aneurysmal development in patients with chronic DeBakey I dissection is not yet clear. ${ }^{15,16}$ For incompletely understood reasons, the residual dissected aorta tends to dilate faster than the nondissected aorta, ${ }^{17}$ aortic expansion appears greatest when the false lumen is partly thrombosed compared with fully thrombosed or fully patent false lumens, ${ }^{18}$ and the onset of distal aortic enlargement is highly unpredictable. ${ }^{19}$ Of note, patients undergoing distal aortic repair related to chronic dissection tend to be younger ${ }^{14,20}$ and may have a lesser atherosclerotic burden than patients without dissection. Endarterectomy of branching vessels is commonly needed in patients with atherosclerosis; however, only 3 of our 171 repairs $(2 \%)$ of chronicdissection-related TAAA involved concomitant endarterectomy, compared with $33 \%$ of 823 TAAA repairs that we recently reported, ${ }^{12}$ and up to $51 \%$ of octogenarians with TAAA repair (unpublished data). Thus, we speculate that most aneurysms in the current series 

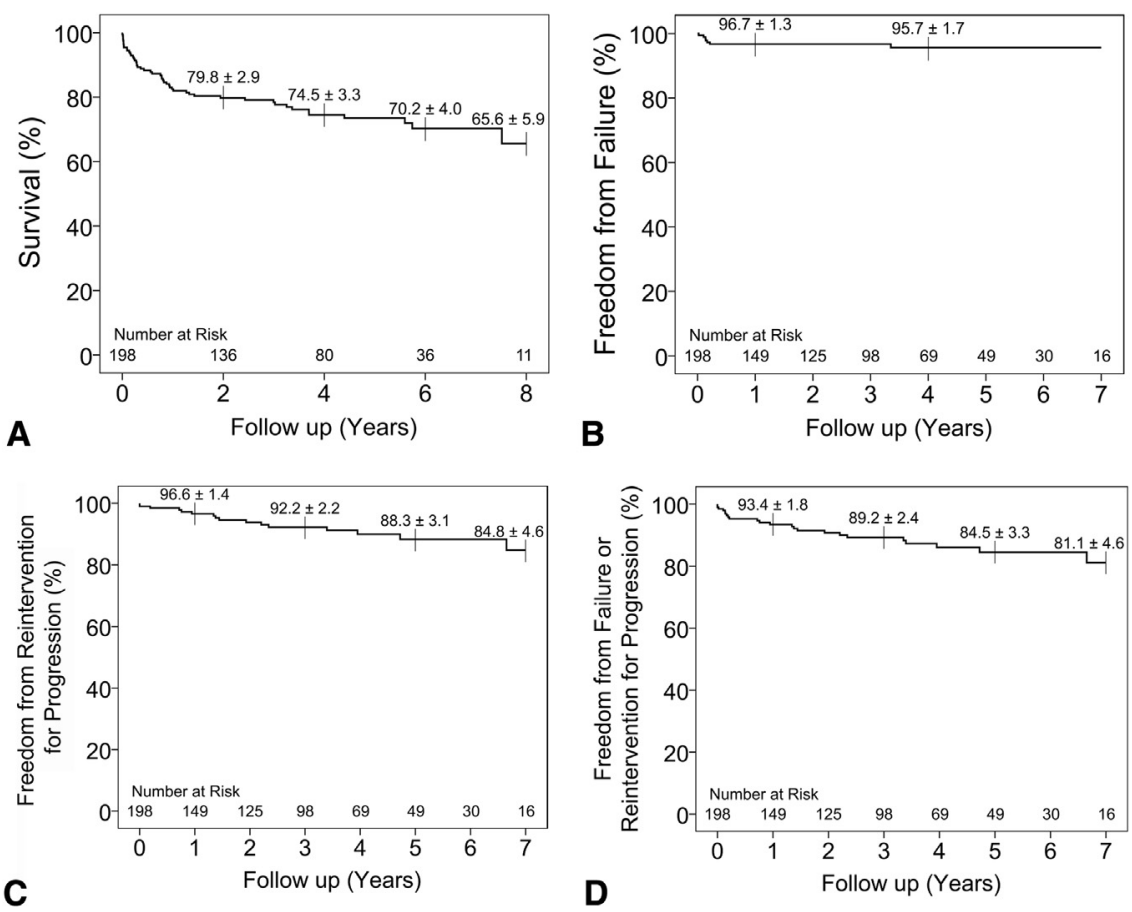

FIGURE 1. Kaplan-Meier curves regarding 198 distal aortic repairs in patients with chronic DeBakey type I aortic dissection showing (A) survival estimate, (B) freedom from repair failure, (C) freedom from reintervention for disease progression, and (D) freedom from repair failure or reintervention for disease progression.

probably resulted from factors other than the atherosclerotic process.

Site-specific repair failure (Table E2) was rare but often deadly $(5 / 7 ; 71 \%)$. Although the presence of pseudoaneurysm was uncommon both preoperatively $(\mathrm{n}=1)$ and postoperatively $(n=3)$, it appears to be the most easily treated failure; 2 of 3 patients survived this complication after rescue with an endovascular graft-within-a-graft approach. ${ }^{21}$ Three of 7 failures occurred in cases involving the extraction of previously placed stent-grafts; as detailed in a previous publication, ${ }^{22}$ repair in such cases is often complicated by preoperative infection or fistula. Likewise, the development of postoperative fistula was difficult to treat-both of the affected patients died.

Survivors of DeBakey type I aortic dissection clearly face an uncertain future regarding the progression of aortic disease; aortic events commonly take place over 2 or 3 decades and often necessitate multiple aortic interventions. Most patients had a complex history of both preoperative and postoperative aortic repair. In approximately one third of patients $(n=61)$, the full aortic arch was replaced preoperatively. Seven patients had subsequent repair of the aortic arch (including 3 reversed elephant trunk completions); 6 patients survived repair, and the only death was related to concomitant aortic root replacement due to graft infection. Thus, in approximately two thirds of patients, the aortic arch did not dilate sufficiently to warrant operative reintervention. Although antegrade TEVAR and FET approaches in acute DeBakey type I aortic dissection are thought to be more useful in preventing late distal aortic events than in treating the aortic arch per se, early experience with modified FET approaches show that late reintervention rates are highest in FET approaches (25\%) compared with endovascular repair for other aortic pathologies, such as for chronic type B dissection (12\%) or infection $(20 \%)$; these FET reinterventions were performed because of poor remodeling of the distal aorta and persistent patency of the false lumen. ${ }^{23}$ In addition, the enhanced risk of spinal cord ischemia during antegrade TEVAR and FET procedures remains a concern. 3,24

Thoracic endovascular repair is now approved for use in aortic dissection and is a tempting strategy for patients and clinicians alike, largely because of the purported reduction in operative death. However, it is not yet clear that such repair slows aortic expansion in cases of chronic dissection, especially the extensive dissection that is present in DeBakey type I pathology. Emerging data suggest that the need for reintervention is greater after TEVAR for chronic distal aortic dissection than after TEVAR for aneurysm. ${ }^{25}$ Moreover, endograft extraction after TEVAR for such dissection in not uncommon; this seems to be related to the persistent growth of the false lumen, ${ }^{26,27}$ and extremely rapid aortic dilatation has been documented after endovascular repair in the chronically dissected aorta. ${ }^{22}$ 


\section{Study Limitations}

Limitations of this report include that it is a single surgical practice experience, with a potential for referral bias and includes in part retrospective data. In addition, we were unable to determine the cause of late death in 9 patients. It is possible that some or all of these deaths were aortic related and involved rupture of previously unreplaced aortic segments; significant portions of the aortic arch remained in approximately half of the cases (full arch replaced in 4 patients), and most had a significant portion of the distal aorta replaced (extent II TAAA repair in 7 patients). These deaths could represent an undetermined repair failure, such as the rupture of a pseudoaneurysm or patch aneurysm. Furthermore, the 6 patients without current follow-up and whom the SSDI shows to be alive could have had a nonlethal repair failure. In many repairs, it was not possible to elucidate factors related to the onset and progression of DeBakey type I aortic dissection; this is mainly because acute proximal aortic dissection necessitates immediate repair, whereas most repairs for chronic distal aortic dissection are elective, and tertiary centers of expertise are commonly sought out. This referral pattern of patients who were initially treated outside our geographic location $(\mathrm{n}=165)$ may have contributed to the difficulty in obtaining late clinical follow-up.

\section{CONCLUSIONS}

In survivors of DeBakey type I aortic dissection, it is difficult to predict whether and when late distal aortic repair will be necessary, so adherence to a lifelong imaging surveillance protocol is crucial. Patients should be counseled regarding the progressive nature of extensive aortic dissection and made aware that multiple interventions may be needed. If and when open distal aortic repair is needed, patients should be assured that open repair of the descending thoracic or thoracoabdominal aorta poses a low risk of early mortality or serious morbidity and that late aortic events are unlikely.

The authors thank Laurie Fondren for managing subject enrollment, Scott A. Weldon, MA, CMI, for creating the images, and Stephen N. Palmer, PhD, ELS, for providing editorial support.

\section{References}

1. Preventza O, Cervera R, Cooley DA, Bakaeen FG, Mohamed AS, Cheong BY, et al. Acute type I aortic dissection: traditional versus hybrid repair with antegrade stent delivery to the descending thoracic aorta. J Thorac Cardiovasc Surg. 2014;148:119-25.

2. Roselli EE, Rafael A, Soltesz EG, Canale L, Lytle BW. Simplified frozen elephant trunk repair for acute DeBakey type I dissection. J Thorac Cardiovasc Surg. 2013;145:S197-201.

3. Di Eusanio M, Castrovinci S, Tian DH, Folesani G, Cefarelli M, Pantaleo A, et al. Antegrade stenting of the descending thoracic aorta during DeBakey type 1 acute aortic dissection repair. Eur J Cardiothorac Surg. 2014;45: 967-75.
4. Vallabhajosyula P, Szeto WY, Pulsipher A, Desai N, Menon R, Moeller P, et al. Antegrade thoracic stent grafting during repair of acute Debakey type I dissection promotes distal aortic remodeling and reduces late open distal reoperation rate. J Thorac Cardiovasc Surg. 2014;147:942-8.

5. LeMaire SA, Miller CC III, Conklin LD, Schmittling ZC, Köksoy C, Coselli JS. A new predictive model for adverse outcomes after elective thoracoabdominal aortic aneurysm repair. Ann Thorac Surg. 2001;71:1233-8.

6. Coselli JS, LeMaire SA, Weldon SA. Extent II repair of thoracoabdominal aortic aneurysm secondary to chronic dissection. Ann Cardiothorac Surg. 2012;1: 394-7.

7. Köksoy C, LeMaire SA, Curling PE, Raskin SA, Schmittling ZC, Conklin LD, et al. Renal perfusion during thoracoabdominal aortic operations: cold crystalloid is superior to normothermic blood. Ann Thorac Surg. 2002;73: $730-8$.

8. LeMaire SA, Jones MM, Conklin LD, Carter SA, Criddell MD, Wang XL, et al. Randomized comparison of cold blood and cold crystalloid renal perfusion for renal protection during thoracoabdominal aortic aneurysm repair. J Vasc Surg. 2009; 49:11-9.

9. Hiratzka LF, Bakris GL, Beckman JA, Bersin RM, Carr VF, Casey DE Jr, et al. 2010 ACCF/AHA/AATS/ACR/ASA/SCA/SCAI/SIR/STS/SVM guidelines for the diagnosis and management of patients with Thoracic Aortic Disease: a report of the American College of Cardiology Foundation/American Heart Association Task Force on Practice Guidelines, American Association for Thoracic Surgery, American College of Radiology, American Stroke Association, Society of Cardiovascular Anesthesiologists, Society for Cardiovascular Angiography and Interventions, Society of Interventional Radiology, Society of Thoracic Surgeons, and Society for Vascular Medicine. Circulation. 2010; 121:e266-369.

10. Engelfriet PM, Boersma E, Tijssen JG, Bouma BJ, Mulder BJ. Beyond the root: dilatation of the distal aorta in Marfan's syndrome. Heart. 2006;92: $1238-43$.

11. Girdauskas E, Kuntze T, Borger MA, Falk V, Mohr FW. Distal aortic reinterventions after root surgery in Marfan patients. Ann Thorac Surg. 2008;86: 1815-9.

12. LeMaire SA, Price MD, Green SY, Zarda S, Coselli JS. Results of open thor acoabdominal aortic aneurysm repair. Ann Cardiothorac Surg. 2012;1: 286-92.

13. Etz CD, Zoli S, Mueller CS, Bodian CA, Di Luozzo G, Lazala R, et al Staged repair significantly reduces paraplegia rate after extensive thoracoabdominal aortic aneurysm repair. J Thorac Cardiovasc Surg. 2010;139: 1464-72.

14. Conway AM, Sadek M, Lugo J, Pillai JB, Pellet Y, Panagopoulos G, et al. Outcomes of open surgical repair for chronic type B aortic dissections. J Vasc Surg. 2014;59:1217-23.

15. LeMaire SA, Russell L. Epidemiology of thoracic aortic dissection. Nat Rev Cardiol. 2011;8:103-13.

16. Wu D, Shen YH, Russell L, Coselli JS, LeMaire SA. Molecular mechanisms of thoracic aortic dissection. J Surg Res. 2013;184:907-24.

17. Coady MA, Rizzo JA, Hammond GL, Kopf GS, Elefteriades JA. Surgical intervention criteria for thoracic aortic aneurysms: a study of growth rates and complications. Ann Thorac Surg. 1999;67:1922-6; discussion 53-8.

18. Tsai MT, Wu HY, Roan JN, Tsai YS, Hsieh PC, Yang YJ, et al. Effect of false lumen partial thrombosis on repaired acute type A aortic dissection. J Thorac Cardiovasc Surg. 2014;148:2140-6.

19. Zierer A, Voeller RK, Hill KE, Kouchoukos NT, Damiano RJ Jr, Moon MR Aortic enlargement and late reoperation after repair of acute type A aortic dissection. Ann Thorac Surg. 2007;84:479-87.

20. Pujara AC, Roselli EE, Hernandez AV, Vargas Abello LM, Burke JM, Svensson LG, et al. Open repair of chronic distal aortic dissection in the endovascular era: implications for disease management. J Thorac Cardiovasc Surg. 2012; 144:866-73.

21. Schwill S, LeMaire SA, Green SY, Bakaeen FG, Coselli JS. Endovascular repair of thoracic aortic pseudoaneurysms and patch aneurysms. J Vasc Surg. 2010;52: 1034-7.

22. LeMaire SA, Green SY, Kim JH, Sameri A, Parenti JL, Lin PH, et al. Thoracic or thoracoabdominal approaches to endovascular device removal and open aortic repair. Ann Thorac Surg. 2012;93:726-33.

23. Szeto WY, Desai ND, Moeller P, Moser GW, Woo EY, Fairman RM, et al. Reintervention for endograft failures after thoracic endovascular aortic repair. J Thorac Cardiovasc Surg. 2013;145:S165-70. 
24. Tian DH, Wan B, Di Eusanio M, Black D, Yan TD. A systematic review and meta-analysis on the safety and efficacy of the frozen elephant trunk technique in aortic arch surgery. Ann Cardiothorac Surg. 2013;2: 581-91.

25. Scali ST, Beck AW, Butler K, Feezor RJ, Martin TD, Hess PJ, et al. Pathologyspecific secondary aortic interventions after thoracic endovascular aortic repair. J Vasc Surg. 2014;59:599-607.

26. Roselli EE, Abdel-Halim M, Johnston DR, Soltesz EG, Greenberg RK, Svensson LG, et al. Open aortic repair after prior thoracic endovascular aortic repair. Ann Thorac Surg. 2014;97:750-6.

27. Miyahara S, Nomura Y, Shirasaka T, Taketoshi H, Yamanaka K, Omura A, et al. Early and midterm outcomes of open surgical correction after thoracic endovascular aortic repair. Ann Thorac Surg. 2013;95:1584-90.

\section{Discussion}

Dr D. Craig Miller (Stanford, Calif). Joe, that was perfect. Crisp and quick. I want to thank you because I believe I heard the term "Stanford type A" once. Appreciate that.

Dr Coselli. You're welcome.

Dr Miller. We have several balls, or unanswered questions, in the air here. The simplest question actually is probably the one you answered today. We know the numerator consisting of the number of people who required another downstream operation, and you have shown clearly using modern open surgical techniques that the risk of these reoperations is low and the 5-year durability is reasonable. Eric Roselli, the late Roy Greenberg, Lars Svensson, and the Cleveland Clinic group have shown that endovascular TEVAR or open surgical repair of descending aortic chronic dissections is associated with a similarly low operative risk and similar short-term outcomes. Not to get sidetracked, whether TEVAR is effective treatment for chronic dissections of the DTA is a separate, controversial topic begging for the proper randomized prospective clinical trial. Nonetheless, we all can agree on the answer to the first question: When necessary, surgical repair of the downstream descending or thoracoabdominal chronic aortic dissection in experienced, high-volume centers is relatively safe and efficacious.

The bigger unanswered question is what is the denominator? We need this number to estimate how many patients surviving an acute type A dissection eventually need something done downstream and characterize which patients are at higher risk of reoperation, for example, possibly those with a connective tissue disorder, to learn what can we do at the first operation to reduce the incidence of late reoperation and sudden, unexplained late deaths. You mentioned that some of these patients die later on and some may die of downstream aortic complications because they did not undergo reoperation, an area ripe for potential improvement.

So what we can do better during the initial acute dissection operation in patients who are at higher risk for subsequent downstream aortic false lumen enlargement of the thoracoabdominal chronic dissection? Dr Kazui in Japan (eg, total arch replacement in selected patients with the Marfan syndrome), Daniel Loisance at the Hospital Môndor in Paris, and Marc Moon at Washington University have analyzed if performing a more radical operation the first time reduces the need for subsequent downstream reoperation, but none have shown success. As exemplified by the report from Paris by Loisance and colleagues, the incidence of reoperation paradoxically increases over time because our threshold to do something downstream declines over the years, that is, our indications for reintervention become more aggressive. So, we have a "moving goal posts" problem, which makes it tough to answer this question short of a randomized prospective clinical trial.

Nonetheless, you mentioned adding a stent-graft or FET in the DTA at the time of the initial acute dissection operation. This seems to be the most popular technique being tried now, as your Baylor team, Eric Roselli at the Cleveland Clinic, Alberto Pochettino and others in the United States, several European groups, and Dr Sun in Beijing often place a standard stent-graft into the distal end of the replacement graft, but in Europe a specialty hybrid device (an open replacement graft combined with a stent-graft) is placed in the true lumen of the proximal DTA during the initial emergency arch/ascending aortic replacement hoping to reduce the incidence of late downstream false aneurysmal degeneration and need for reoperation.

How are we going to sort out whether a more radical approach like this at the time of the initial operation - and in which patients it is needed-is justified without knowing the denominator and given the fact that our reintervention endpoints are changing over time? As you yourself have stated, any time you do something beyond the left subclavian at the time of the first operation for acute type A dissection you add incremental risk, namely, the risk of paraplegia. Further, the new German GERAADA registry data demonstrate that if one replaces the arch when you otherwise would not have to, you increase the early acute type A dissection operative mortality rate by $10 \%$ in Germany. How do we sort out this conundrum? Who is going to pay for the randomized clinical trial that is obviously required?

Dr Coselli. Well, thank you, Dr Miller. I don't have an answer for this conundrum, and the fact that you don't either is probably why it remains a conundrum. Clearly in this work, we are dealing with the numerator and not the denominator, and, as at most of our institutions, many of these patients come from far and wide and are extremely difficult to follow up. So, determining the denominator is challenging.

You are absolutely right. When we have tried an expanded approach to repair at the initial operation, with an aim to reduce the likelihood of a second operation, we do that at a price. Expanded approaches have included total arch replacement, and, as you mentioned, the operation de jour, which is to place a stent graft in the true lumen at the initial procedure. These approaches increase early risk; as you mentioned from the German Registry for Acute Aortic Dissection Type A (GERAADA) study, the total arch approach carries a $10 \%$ risk in mortality, and in the latter there is a risk of paraplegia. But trying to balance out these initial morbidities and mortalities with what is best in the long term is what we are trying to establish. Such work would give us a benchmark by which to compare these other techniques, both in the short term and the long term, but a great deal more work is going to have to be done to sort this out.

Dr E. Roselli (Cleveland, Ohio). My question is about the fate of the aortic arch. I noted that you reoperated on 7 of those. Were those patients who had the reverse elephant trunk technique, numbers 1 and 2, the ones in whom the native arch was left behind, was that chronically dissected, and how do you make the decision about how to operate on that intervening segment? 
Dr Coselli. For the last part, the decision to operate on the arch is primarily determined by the rate of increase in size, the development of symptoms, and the absolute size, using approximately 6 to $6-1 / 2 \mathrm{~cm}$ diameter in that particular location. All of the patients in this group had chronic dissection of the transverse aortic arch. As we all well know, the arch is usually the last thing to dilate. This adds to the discussion about how aggressive to be at the initial operation, and only a couple of patients in this series have returned for arch repair after undergoing a reverse elephant trunk procedure. 

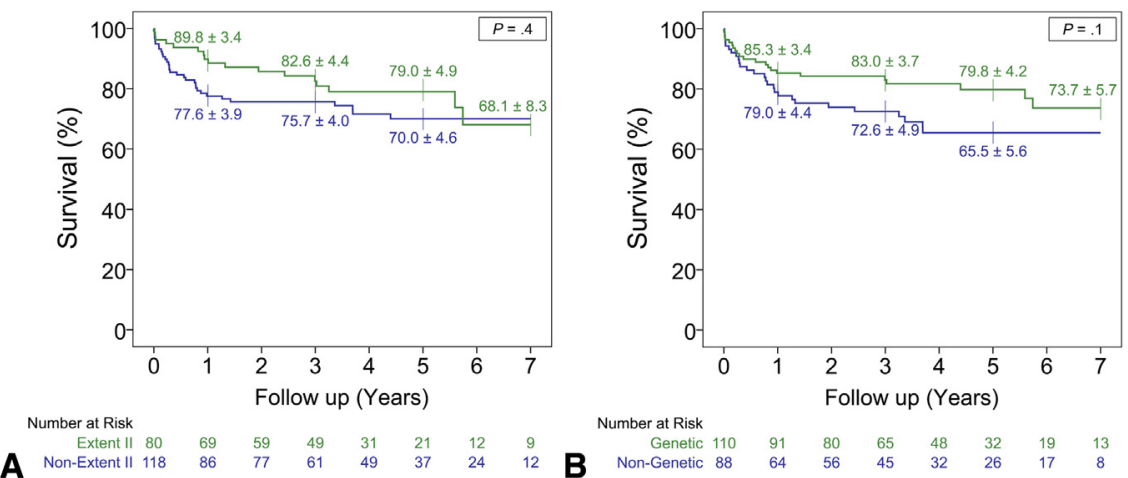

FIGURE E1. Actuarial survival stratified by extent II TAAA repair versus all other repairs (A) and by genetic disorder versus no genetic disorder (B). Patients in both of these selected subgroups were substantially younger when they underwent distal aortic repair-median ages were 51.8 versus 58.7 years and 47.1 versus 62.0 years, respectively. The comparisons were computed using the log rank (Mantel-Cox), Breslow (generalized Wilcoxon), and TaroneWare tests; the $P$ value reported is derived from the log-rank test.

TABLE E1. Early outcomes by extent II thoracoabdominal aortic aneurysm repair and genetic disorder

\begin{tabular}{|c|c|c|c|c|c|}
\hline Complication & $\begin{array}{c}\text { All repairs }(\mathbf{n}=198) \\
\text { No. }(\%)\end{array}$ & $\begin{array}{l}\text { Extent II TAAA repair } \\
(\mathbf{n}=\mathbf{8 0}) \text { No. }(\%)\end{array}$ & $P$ value & $\begin{array}{l}\text { Genetic disorder } \\
(\mathbf{n}=110) \text { No. }(\%)\end{array}$ & $P$ value \\
\hline Adverse outcome (composite endpoint) & $24(12.1)$ & $8(10.0)$ & .5 & $12(10.9)$ & .6 \\
\hline Operative (early) death & $14(7.1)$ & $4(5.0)$ & .3 & $6(5.5)$ & .3 \\
\hline Permanent stroke & $5(2.5)$ & $2(2.5)$ & 1.0 & $1(0.9)$ & .2 \\
\hline Permanent paraplegia & $2(1.0)$ & 0 & .5 & 0 & .2 \\
\hline Permanent paraparesis & $3(1.5)$ & $1(1.3)$ & .6 & $2(1.8)$ & 1.0 \\
\hline Permanent renal failure (need for dialysis) & $9(4.6)$ & $4(5.0)$ & 1.0 & $6(5.5)$ & .7 \\
\hline Cardiac complication & $56(28.3)$ & $24(30.0)$ & .7 & $26(23.6)$ & .1 \\
\hline Pulmonary complication & $78(39.4)$ & $31(38.8)$ & .9 & 37 (33.6) & .064 \\
\hline
\end{tabular}

The $P$ value is as compared with the non-extent II repair group (DTA, extent I, extent III, extent IV) and the nongenetic disorder group, respectively. Adverse event is a composite endpoint that includes operative death (in-hospital or 30-day death) and permanent (present at hospital discharge) stroke, renal failure, paraplegia, or paraparesis. TAAA, Thoracoabdominal aortic aneurysm.

TABLE E2. Site-specific late failures and related reinterventions

\begin{tabular}{|c|c|c|}
\hline Age (y) & POD & Description of event \\
\hline 53 & 50 & $\begin{array}{l}\text { Development of pseudoaneurysm (at mid-descending thoracic level) and intercostal patch aneurysm necessitated } \\
\text { endovascular reintervention by an endograft-within-graft approach; alive at POD } 1868\end{array}$ \\
\hline 50 & 61 & $\begin{array}{l}\text { Hemoptysis after development of aortobronchial fistula and complicated by sepsis after endograft extraction; death } \\
\text { at POD } 62\end{array}$ \\
\hline 63 & 7 & Exsanguination due to aortoesophageal fistula at graft-to-graft anastomosis; death at POD 8 \\
\hline 62 & 1224 & Rupture of pseudoaneurysm of DTA; death at POD 1228 \\
\hline 61 & 78 & Graft infection without open reintervention; death at POD 276 \\
\hline 56 & 38 & $\begin{array}{l}\text { Development of pseudoaneurysm (at suture line of prior elephant trunk and extent II graft) necessitated endovascular } \\
\text { reintervention by an endograft-within-graft approach; additional open repair } 2 \mathrm{~d} \text { later to reattach the visceral patch, } \\
\text { which had dehisced at the proximal anastomosis; alive at POD } 1981\end{array}$ \\
\hline 61 & 52 & Recurrent infection and recurrent aortobronchial fistula in patient with prior endograft extraction; death at POD 204 \\
\hline
\end{tabular}

$D T A$, Descending thoracic aorta; $P O D$, postoperative day. 
TABLE E3. Description of 17 repairs for disease progression

\begin{tabular}{ccrl}
\hline Age $(\mathbf{y})$ & GD & POD & \multicolumn{1}{c}{ Description of event } \\
\hline 22 & Y & 490 & TAAA extent IV repair after DTA repair; alive POD 2436 \\
53 & N & 1443 & TAAA extent III repair after DTA repair; alive POD 1730 \\
59 & Y & 346 & TAAA extent III repair after TAAA extent I repair; alive POD 1263 \\
62 & Y & 277 & TAAA extent III repair after DTA repair; related death at POD 285 \\
32 & Y & 527 & TEVAR of distal aortic arch and proximal edge of replacement graft to treat new symptoms; alive POD 1128 \\
50 & Y & 385 & EVAR after TAAA extent II repair; alive POD 1519 \\
35 & Y & 70 & EVAR after TAAA extent II repair; alive POD 2816 \\
48 & Y & 1483 & EVAR after TAAA extent II repair; alive POD 3024 \\
62 & N & 1725 & EVAR after TAAA extent IV repair; alive POD 3138 \\
66 & N & 854 & Open abdominal aortic repair after TAAA extent IV repair; alive POD 3081 \\
31 & Y & 2430 & Open aortic arch repair (with redo root) after TAAA extent II; alive POD 2662 \\
57 & N & 262 & Open aortic arch repair (with redo root for graft infection) after TAAA extent I; death at POD 284 \\
45 & Y & 2858 & Open aortic arch after TAAA extent II repair with RET; alive POD 2886 \\
59 & N & 1240 & Open aortic arch repair TAAA extent I repair; alive POD 2547 \\
56 & Y & 503 & Open aortic arch repair (with redo aortic root) after TAAA extent II repair; alive POD 1700 \\
35 & Y & 705 & Open aortic arch (with redo ascending repair) after TAAA extent II repair with RET; alive POD 1968 \\
35 & Y & 805 & Open aortic arch repair after TAAA extent II repair with RET; alive POD 1153 \\
\hline
\end{tabular}

DTA, Descending thoracic aorta; $E V A R$, endovascular aortic repair; $G D$, genetic disorder; $P O D$, postoperative day; $R E T$, reverse elephant trunk; TAAA, thoracoabdominal aortic aneurysm; TEVAR, thoracic endovascular aortic repair. 